\title{
FABRICAÇÃO ARTESANAL DE QUEIJO COLONIAL ANALISADA SOB OS CRITÉRIOS DA INSTRUÇÃO NORMATIVA n 30/2013 (MUNICÍPIOS DO TERRITÓRIO DA CANTUQUIRIGUAÇU, PARANÁ, BRASIL)
}

\author{
Artisanal production of Colonial cheese analyzed under \\ Normative Instruction no ${ }^{\circ}$ 30/2013 (municipalities \\ in the Cantuquiriguaçu region, Paraná, Brazil)
}

\begin{abstract}
Ionara Casali Tesser ${ }^{\prime}$, Luciana Oliveira de Fariña ${ }^{l}$, Luciana Bill Mikito Kottwitz ${ }^{l}$, David Esteban Fariña Sosa ${ }^{l}$, Débora Cristina Pramiu ${ }^{l}$
\end{abstract}

\section{RESUMO}

Este estudo foi realizado em 17 propriedades produtoras de queijo colonial artesanal de três municípios do oeste da Cantuquiriguaçu (PR). Por meio de questionário, buscou-se conhecer as condições de produção do leite e da fabricação dos queijos coloniais, para que fossem comparados com os critérios da Instrução Normativa n ${ }^{\circ}$ 30/2013 do MAPA (Ministério da Agricultura, Pecuária e Abastecimento). Os resultados indicaram que em todas as propriedades avaliadas $(100 \%)$ não havia certificação como livres de brucelose e tuberculose, nem programa para controle de mastite, nem de boas práticas de ordenha e de manipulação dos queijos, além de deficiências no controle da qualidade da água, do controle de pragas e da maturação dos queijos. Considerando os critérios da IN30/2013, as propriedades foram consideradas inadequadas para a produção. No entanto, cabe destacar que o município 01 tem implantadas diversas medidas que atendem parcialmente quesitos da legislação, indicando que a implementação de políticas públicas e mais suporte técnico poderão auxiliar os produtores a se tornarem aptos para produção adequada de queijos com leite cru.

Palavras-chave: agricultura familiar; legislação; desenvolvimento rural; políticas públicas.

1 Universidade Estadual do Oeste do Paraná (UNIOESTE), Rua Universitária, 1619, Universitário, 85819110, Cascavel, PR, Brasil. E-mail: ionaratesser@yahoo.com.br

* Autor para correspondência. 


\begin{abstract}
This study took place in 17 rural properties that produce colonial cheese in three towns of the Cantuquiriguaçu region (Paraná state, Brazil). A questionnaire was applied, in order to collect data on the milk and colonial cheese production, so that data could be analyzed according to the Normative Instruction $n^{\circ} 30 / 2013$ from MAPA (Brazilian Ministry of Agriculture, Livestock and Food Supply). The results indicated that the visited farms did not have a certificate attesting them as free from brucellosis and tuberculosis (100\%), nor even a program for mastitis control, nor good practices on milking and handling of cheese, not to mention poor control of water quality, poor pest control and minimum cheese ripening. Thus, according to the criteria from the Normative Instruction $n^{\circ} 30 / 2013$, those farms were considered unsuitable for the production. It is worth noting, however, that one of the towns has already taken measures that partially met requirements of the legislation, indicating that the adoption of public policies and more technical support might assist producers to become apt for the adequate production of cheese from raw milk.
\end{abstract}

Keywords: family farming; legislation; rural development; public policies.

\section{INTRODUÇÃO}

O queijo colonial, também conhecido como queijo serrano é, de acordo com Souza et al. (2003), produzido com leite cru, é semiduro e possui sabor forte. Sua casca é fina, uniforme, lisa, macia e apresenta uma cor amarelo-palha. Sua estrutura interna é esbranquiçada com pequenas olhaduras não distribuídas uniformemente. É um produto comumente fabricado sem um processamento adequado da matéria-prima e a fermentação ocorre por um processo natural. Sabe-se que a matéria-prima do queijo colonial é o leite cru e que sua qualidade pode ser influenciada por muitos fatores, tais como: o manejo, a sanidade, a genética, a alimentação dos rebanhos e a obtenção do leite, seu resfriamento e sua armazenagem, conforme apontam Hartmann et al. (2009). Dessa forma, a saúde da glândula mamária, a higiene de ordenha, o ambiente em que a vaca fica alojada e os procedimentos de limpeza dos equipamentos de ordenha são fatores que afetam diretamente a contaminação microbiana do leite cru (GUERREIRO et al., 2005).
A fabricação de queijos consiste em uma série de operações que vai desde a produção de leite até o último dia de maturação e expedição para o mercado (PIETROWSKI et al., 2008). A fabricação do queijo necessita, assim como em outros alimentos, condições higiênico-sanitárias rigorosas, pois falhas durante o processo de obtenção da matéria prima, bem como em todas as etapas de produção, podem resultar em um produto de má qualidade, podendo provocar infecções e intoxicações aos consumidores (ZAFFARI et al., 2007).

O queijo é considerado um veículo frequente de patógenos de origem alimentar, em especial os queijos frescos artesanais por serem, majoritariamente, elaborados a partir de leite cru e não sofrerem processo de maturação. A contaminação microbiana desses produtos assume destacada relevância tanto para a indústria, pelas perdas econômicas, como para a saúde pública, pelo risco de causar doenças transmitidas por alimentos (FEITOSA et al., 2003).

Segundo Lisita (2005), as más condições higiênico-sanitárias do leite, a refrigeração 
inadequada ou inexistente ao longo da cadeia produtiva e as péssimas condições da fabricação dos queijos, são os principais motivos que envolvem a má qualidade microbiológica dos queijos no Brasil.

Entretanto, o queijo colonial tem importante valor nutricional no cenário brasileiro por possuir altos teores de lipídeos, proteínas e vitaminas. Sua produção é essencialmente artesanal e a tecnologia empregada se constitui de conhecimentos adquiridos por tradição familiar regional e não possui um padrão específico que permita uma conceituação geral. Sua produção é de suma importância para o homem do campo, servindo como importante alternativa para pequenos produtores rurais, que utilizam essa atividade para incrementar a renda familiar. A produção e venda desse tipo de produto também tem uma grande importância para a sociedade, gerando empregos, aumentando a permanência do homem no campo e ajudando na manutenção da cultura e das tradições locais, conforme aponta Oliveira et al. (2010).

Apesar da produção global significativa e da importância financeira para os pequenos produtores da região Sul do país, poucos são os dados existentes a respeito da produção brasileira de queijo colonial, que está concentrada nos estados do Paraná, Santa Catarina e Rio Grande do Sul. Da mesma forma, não existem legislações específicas que caracterizem este tipo de queijo, o que, consequentemente, dificulta sua avaliação e controle.

Devido a isso, os órgãos fiscalizadores dos municípios pesquisados no oeste do território da Cantuquiriguaçu (região do médio centro-oeste do Paraná) não possuem controle sobre as condições higiênico-sanitárias de fabricação, qualidade ou quantidade do produto fabricado para a venda e nem mesmo do controle dos fabricantes desse tipo de queijo artesanal, o que causa preocupação aos órgãos fiscalizadores e consumidores.
A produção informal dos queijos coloniais não é uma prática realizada apenas nos municípios da Cantuquiriguaçu. Muitos outros municípios possuem pequenas agroindústrias onde, normalmente, o queijo é manipulado sem condições higiênico-sanitárias mínimas, de forma rudimentar e em local inadequado, como se notará na pesquisa aqui apresentada. Esta prática acaba sendo frequente, porém, sua proibição pode acarretar problemas econômicos para populações que sobrevivem somente desse tipo de atividade ou a utilizam como um incremento da renda familiar, conforme constatado em nossa pesquisa.

De acordo com Mousquer (2007) e Viana (2013), grande parte dos agricultores da região do oeste do Paraná produz o queijo colonial com tecnologia semelhante àquela do queijo Minas artesanal, porém, dados concretos a respeito da tecnologia de produção, composição e comercialização são escassos. Parte do objetivo desta pesquisa foi acompanhar, descrever e analisar essa produção.

A Instrução Normativa ${ }^{\circ} 30$ (IN30), de 07 de agosto de 2013, do Ministério da Agricultura Pecuária e Abastecimento (MAPA) estabelece condições mínimas que permitem que os queijos artesanais sejam tradicionalmente elaborados a partir de leite cru, inclusive que estes sejam "maturados por um período inferior a 60 (sessenta) dias, quando estudos técnico-científicos comprovarem que a redução do período de maturação não compromete a qualidade e a inocuidade do produto" (BRASIL, 2013). Ainda assim, existem ainda vários problemas associados à produção de queijos artesanais com leite cru. Entre os problemas, destaca-se a limitação financeira dos produtores, a falta de assistência técnica, a dificuldade para o acompanhamento da qualidade do leite e da água das propriedades rurais, bem como do acompanhamento da sanidade do rebanho e 
a falta de apoio do poder público dos municípios onde atuam esses agricultores para ajudar com soluções viáveis para a atividade.

Por isso, destaca-se que políticas públicas tais como cursos, visitas, treinamentos, entre outros, poderiam ser aplicadas para ajudar a solucionar os problemas relativos a esta atividade, não somente com a implantação de políticas de fiscalização e punição, como normalmente ocorre da parte das Secretarias de Vigilância Sanitárias municipais. Seria também importante o auxílio efetivo e continuado por parte das Secretarias de Agricultura de tais municípios, o que possibilitaria ao agricultor atender às exigências impostas pela legislação e a manter a qualidade do produto que será levado ao consumidor.

O objetivo deste trabalho foi realizar um diagnóstico das etapas e do processo envolvido na fabricação de queijos coloniais a partir de leite cru por agricultores familiares de três municípios da região oeste do Território da Cantuquiriguaçu (PR) e verificar se estes se adequariam aos critérios estabelecidos pela Instrução Normativa $n^{\circ} 30$ (IN30) do Ministério da Agricultura, Pecuária e Abastecimento (BRASIL, 2013) que descreve condições para realização desta atividade no Brasil. Não se trata, portanto, de uma investigação das características físico-químicas dos produtos acabados, mas de uma análise dos procedimentos, com ênfase nas formas de fazer, das práticas costumeiras dos produtores e se essas se enquadram, ou não, à legislação.

\section{MATERIAL E MÉTODOS}

Foram pesquisados e avaliados os processos de produção dos queijos coloniais artesanais produzidos a partir de leite cru em três municípios localizados na região oeste do Território da Cantuquiriguaçu (PR). Foram visitadas 17 propriedades rurais dedicadas à produção de queijo, cujo acesso foi intermediado com apoio das Secretarias de Agricultura e das agências do Instituto Paranaense de Assistência Técnica e Extensão Rural (Emater) de cada município. Foram 12 propriedades no "Município 1", três propriedades no "Município 2" e duas propriedades no "Município 3", número restrito pelo cronograma da pesquisa e abertura dos proprietários a receber as visitas, que ocorreram entre os meses de julho de 2013 e janeiro de 2014 .

Foram visitadas todas as 17 propriedades, nas quais se observaram as condições gerais de produção do queijo, em alguns casos acompanhando todas as etapas do processo. Para coletar informações de maneira uniforme, aplicou-se aos responsáveis pela produção do leite e do queijo nessas propriedades um questionário padrão desenvolvido por Tesser (2014). O questionário, que se encontra resumido na Tabela 1 , incluía questões sobre a sanidade animal, boas práticas de ordenha, o controle de qualidade do leite, o controle de qualidade da água, as condições de produção do queijo e as condições de transporte para comercialização do queijo colonial e, posteriormente, essas informações foram analisadas.

As respostas obtidas com o questionário foram tabeladas e analisadas. A pesquisa foi avaliada e aprovada pelo Comitê de Ética em Pesquisa da Universidade Estadual do Oeste do Paraná (UNIOESTE) e aprovado conforme Parecer CAE n ${ }^{\circ}$ 15302013.8.0000.0107.

\section{RESULTADOS E DISCUSSÃO}

Os resultados obtidos a partir das respostas dos questionários, referentes às condições de produção do leite e do queijo, bem como dos procedimentos empregados na fabricação e condições de embalagem e rotulagem desse produto, estão descritos nas tabelas a seguir e são discutidos na sequência à luz da Instrução Normativa $n^{\circ} 30$ (BRASIL, 2013). 
Tabela 1 - Resumo dos questionamentos respondidos pelos produtores - questionário estruturado

\begin{tabular}{l|l}
\hline 1. Qual tipo de ordenha realiza? & ( ) manual $\quad$ ( ) mecânica \\
\hline 2. Realiza lavagem dos tetos? & $\begin{array}{l}\text { ( ) não } \\
\text { Se sim, como? }\end{array}$ \\
\hline 3. Realiza pré-dipping dos animais antes da ordenha? & ( ) sim \\
\hline 4. Realiza pós-dipping dos animais após a ordenha? & ( ) sim \\
\hline 5. Qual o local que se faz a produção do queijo colonial? & $\begin{array}{l}\text { ( ) Na cozinha da própria casa } \\
\text { ( ) Local separado }\end{array}$ \\
\hline
\end{tabular}

6. Quais os utensílios utilizados na fabricação do queijo colonial?

7. Quais os ingredientes utilizados na elaboração do queijo colonial?

8. Como é feita a adição do sal?

9. O queijo sofre algum processo de maturação?

( ) não

( ) $\operatorname{sim}$

Se sim, como?

10. Tempo de maturação?

\begin{tabular}{l|ll}
\hline $\begin{array}{l}\text { 11. O queijo recebe algum tipo de embalagem antes } \\
\text { da comercialização? }\end{array}$ & ( ) sim & ( ) não \\
\hline 12. Armazenamento do queijo colonial & Tipo? Condições? \\
\hline 13. A embalagem possui rótulo? & $\begin{array}{l}\text { ( ) não } \\
\text { Adequado? }\end{array}$ \\
\hline
\end{tabular}

\section{Avaliação das condições de produção do leite}

\section{Sanidade Animal}

Na Tabela 2 são apresentados os resultados da avaliação do controle da sanidade animal realizado nas propriedades visitadas.

No que se refere ao controle dos produtores de queijo em relação às zoonoses, observou-se que as propriedades não possuem certificação como livres de tuberculose e brucelose, porém em 76\% (12) das propriedades realizava-se o controle anual dessas doenças com aplicação de vacinas.

No Brasil, o Programa Nacional de Controle e Erradicação da Brucelose e Tuberculose Animal - PNCEBT tem como objetivo combater essas enfermidades, reduzir sua incidência e prevalência, a fim de minimizar os prejuízos econômicos, diminuindo o impacto negativo dessas zoonoses na saúde pública e promover a competitividade da pecuária nacional. Este programa define uma estratégia de certificação de propriedades livres ou monitoradas, no qual essas enfermidades são controladas com rigor (BRASIL, 2006).

Quanto o controle de mastite, $76 \%$ $(\mathrm{n}=12)$ das propriedades realizam diariamente os exames de mastite clínica e subclínica, porém não possuem o Programa de Controle de Mastite implantado. Já 24\% $(n=5)$ das propriedades não realizam os exames de mastite clínica e subclínica e também não possuem controle de mastite implantado.

Segundo Costa (1998), a mastite é uma das mais complexas e dispendiosas doenças da produção leiteira. Seu efeito é notado, 
principalmente, pela redução na produção e as alterações na composição do leite. Ao mesmo tempo, representa um risco potencial à saúde pública, em decorrência da disseminação de patógenos causadores de zoonoses e toxinas produzidas pelos microrganismos do leite. Para o produtor, as perdas são de grande magnitude. Elas se apresentam no maior descarte de animais, gastos com medicamentos, redução na produção e descarte de leite. Sua detecção é de grande importância e é estabelecida através da Instrução Normativa $n^{\circ} 62$, de 29 de dezembro de 2011 (BRASIL, 2011).

\section{Boas Práticas de Ordenha}

Encontram-se, na Tabela 3, os resulta- dos da avaliação as boas práticas de ordenha realizadas nas propriedades visitadas.

Para avaliar se as propriedades possuiam as boas práticas de ordenha foram observados vários itens de maior importância dentro das práticas realizadas. No que diz respeito ao tipo de ordenha, foi observado que $71 \%$ $(\mathrm{n}=12)$ das propriedades ordenham na forma mecânica, e $29 \%(n=5)$ ordenham na forma manual. E, em relação ao processo de lavagem dos tetos, se observou que $100 \%(n=17)$ das propriedades lavam os tetos dos animais antes da ordenha e utilizam somente água corrente para realização desse processo, sendo que essa água corrente era proveniente de poços artesianos das propriedades.

Sabe-se que somente água não é suficiente para realizar o processo de limpeza

Tabela 2 - Avaliação do controle da sanidade animal realizado nas propriedades visitadas $(\mathrm{n}=17 *)$

\begin{tabular}{lccc}
\hline \multicolumn{1}{c}{ Exigências da IN30 } & $\begin{array}{c}\text { Município 1 } \\
\mathrm{n}=12\end{array}$ & $\begin{array}{c}\text { Município 2 } \\
\mathrm{n}=03\end{array}$ & $\begin{array}{c}\text { Município 3 } \\
\mathrm{n}=02\end{array}$ \\
\hline $\begin{array}{l}\text { Propriedade certificada como livre } \\
\text { de tuberculose e brucelose }\end{array}$ & $0 * *$ & 0 & 0 \\
$\begin{array}{l}\text { Programa de Controle de Mastite } \\
\text { Realização de exames para detecção } \\
\text { de mastite clínica }\end{array}$ & 0 & 0 & 0 \\
$\begin{array}{l}\text { Realização de exames para detecção } \\
\text { de mastite subclínica }\end{array}$ & $12(100 \%)$ & 0 & 0 \\
\hline
\end{tabular}

*n $=17$ : número de propriedades visitadas.

**Controle e vacinação uma vez por ano.

Tabela 3 - Avaliação das boas práticas de ordenha realizadas nas propriedades visitadas $\left(\mathrm{n}=17^{*}\right)$

\begin{tabular}{cccc}
\hline Exigências da IN30 & $\begin{array}{c}\text { Município 1 } \\
\mathrm{n}=12\end{array}$ & $\begin{array}{c}\text { Município 2 } \\
\mathrm{n}=03\end{array}$ & $\begin{array}{c}\text { Município 3 } \\
\mathrm{n}=02\end{array}$ \\
\hline $\begin{array}{c}\text { Programa de Boas Práticas de Ordenha } \\
\text { Controle dos operadores }\end{array}$ & $\begin{array}{c}12 * * \\
0\end{array}$ & 0 & $1 * *$ \\
\hline
\end{tabular}

$*_{\mathrm{n}}=17$ : número de propriedades visitadas.

**Atende parcialmente a alguns quesitos das boas práticas de ordenha. 
adequada dos tetos, o que pode afetar a qualidade da ordenha e do leite resultante dela. Segundo Tronco (2013), a carga bacteriana do leite pode aumentar quando os tetos não são devidamente lavados.

Quanto à prática da filtração do leite antes da estocagem, notou-se que $76 \%(\mathrm{n}=13)$ das propriedades não realizam esse processo, enquanto que $24 \%(n=4)$ realizam algum processo de filtração antes de estocar o leite. O processo de filtração ajuda a eliminar algumas impurezas macroscópicas e a manter a qualidade ao leite. Segundo Bezerra (2008), mesmo que se tenham tomado todos os cuidados necessários após a ordenha, o leite poderá conter algumas impurezas como: insetos, pêlos ou terra. Portanto, a etapa da filtração é importante para se obter um leite de boa qualidade. Considerando os itens observados, nenhuma das propriedades avaliadas possui boas práticas de ordenha implantadas.

No que tange ao controle dos operadores, verificou-se que nenhuma das propriedades realiza o acompanhamento do estado de saúde com frequência e nem cuidados específicos preconizados para o trabalho, tais como o uso de roupas claras e limpas, de preferência um uniforme específico (gorro, macacão ou jaleco, calça e botas) usado apenas para essa finalidade (BRASIL, 2011). Os cabelos devem estar presos e cobertos e o operador do equipamento de ordenha deve, no seu manuseio, conservar as mãos sempre limpas. No momento da ordenha, o ordenhador deve se concentrar apenas nessa função, não realizando outros trabalhos ao mesmo tempo, para evitar contaminação (BRASIL,
2000). O que foi observado é que muitos dos produtores utilizam gorro, enquanto outros apenas prendem o cabelo. Poucos retiravam seus adornos para executar as atividades e apenas três dos produtores observados utilizava algum tipo de avental.

\section{Controle da Qualidade do Leite}

$\mathrm{Na}$ Tabela 4 são apresentados os resultados da avaliação do controle de qualidade do leite nas propriedades visitadas.

Nenhum produtor visitado realiza qualquer tipo de exame de qualidade do leite utilizado na fabricação dos queijos. Conforme estabelece a Instrução Normativa $n^{\circ} 30$ de 2013 (BRASIL, 2013) é necessário que sejam realizados exames de qualidade em Laboratório participante da Rede Brasileira de Qualidade do Leite (RBQL).

Os testes de qualidade que são realizados pela RBQL são as análises de contagem de células somáticas (CCS) e contagem de bactérias totais (CBT) e adicionalmente se determina a composição do leite em relação aos teores de gordura, proteínas e lactose. Segundo a Instrução Normativa $n^{0} 62$ (BRASIL, 2011) a contagem de CCS deve possuir no máximo $5,0 \times 10^{5} \mathrm{CS} / \mathrm{mL}$ e CBT máxima de $3,0 \times 10^{5} \mathrm{UFC} / \mathrm{ml}$; para proteína, valores mínimos de 2,9\%; e, por fim, para gordura, valor mínimo de $3,0 \%$.

\section{Controle da Qualidade da Água}

Os resultados da avaliação da realização do controle de qualidade da água nas

Tabela 4 - Avaliação do controle de qualidade do leite realizado nas propriedades visitadas $(\mathrm{n}=17 *)$

\begin{tabular}{cccc}
\hline Exigências da IN30 & $\begin{array}{c}\text { Município 1 } \\
\mathrm{n}=12\end{array}$ & $\begin{array}{c}\text { Município 2 } \\
\mathrm{n}=03\end{array}$ & $\begin{array}{c}\text { Município 3 } \\
\mathrm{n}=02\end{array}$ \\
\hline Controle de qualidade do leite & 0 & 0 & 0 \\
\hline
\end{tabular}

*n = 17: número de propriedades visitadas. 
propriedades visitadas, encontram-se abaixo, na Tabela 5 .

Foi observado que a água de todas as propriedades avaliadas é proveniente de poços artesianos, não sofrendo cloração. Foi relatado que o controle da potabilidade, conforme estabelecido pela Instrução Normativa

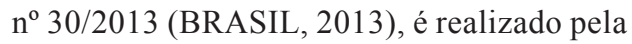
Secretaria de Saúde do Estado do Paraná (SESA) por meio da Secretaria de Vigilância Sanitária de cada município e, pelo menos uma vez ao ano, são realizadas análises microbiológicas e análise de turbidez da água de cada propriedade. Destaca-se que este controle da qualidade da água é uma política pública estabelecida pelo Ministério da Saúde (ANVISA, 1997) e adotada e apoiada financeiramente pelo estado do Paraná.

Segundo a Circular no 175/2005 do Departamento de Inspeção de Produtos de Origem Animal (DIPOA) e da Coordenação Geral de Programas Especiais (CGPE) (BRASIL, 2005), pertencentes ao MAPA, é de capital importância para qualquer indústria de alimentos dispor de água potável em quantidade suficiente para o desenvolvimento de suas atividades e que atenda os padrões fixados pela legislação brasileira vigente. A manutenção de tais padrões implica na necessidade de monitoramento, que deve ser executado pelo estabelecimento e verificado pelo Serviço de Inspeção Federal, tendo como referência os parâmetros da citada legislação e executados de acordo com as particularidades inerentes à modalidade de suprimento de cada estabelecimento (BRASIL, 2005).
Guerreiro et al. (2005), afirmam que entre as fontes ambientais de contaminação do leite está a água usada na limpeza dos equipamentos. A água utilizada para esses fins deve ser potável, com baixa contaminação, pois além de constituir um veículo de transmissão de agentes patogênicos para seres humanos e animais, a água não tratada pode constituir uma via de transmissão de agentes causadores de mastite, como Staphylococcus aureus e coliformes (TOMICH et al., 2005). A água contaminada pode, ainda, ser uma fonte de Pseudomonas spp., coliformes e outras bactérias, conforme apontam Elmoslemany et al. (2010).

\section{Condições de Produção dos Queijos}

Na Tabela 6 encontram-se expostos os resultados da avaliação das condições de produção dos queijos nas propriedades visitadas.

Para se avaliar a existência do programa de Boas Práticas de Fabricação de queijos nas propriedades visitadas, vários quesitos associados à produção dos queijos foram verificados, os quais são discutidos a seguir.

De acordo com 65\% $(\mathrm{n}=11)$ dos entrevistados, o queijo colonial é produzido em salas, ou cozinhas adaptadas, chamadas de "casa do queijo", separadas da cozinha da residência, destinadas somente à produção desses produtos. Um total de $35 \%(n=6)$ produzem os queijos na cozinha da própria residência.

Observou-se que $88 \%(\mathrm{n}=15)$ utilizam utensílios em aço inox e $12 \%(\mathrm{n}=2)$

Tabela 5 - Controle de qualidade da água realizado nas propriedades visitadas $\left(\mathrm{n}=17^{*}\right)$

\begin{tabular}{cccc}
\hline Exigências da IN30 & $\begin{array}{c}\text { Município 1 } \\
\mathrm{n}=12\end{array}$ & $\begin{array}{c}\text { Município 2 } \\
\mathrm{n}=03\end{array}$ & $\begin{array}{c}\text { Município 3 } \\
\mathrm{n}=02\end{array}$ \\
\hline $\begin{array}{c}\text { Controle de potabilidade da água } \\
\text { Cloração da água }\end{array}$ & $\begin{array}{c}12 \\
0\end{array}$ & 03 & 02 \\
\end{tabular}

*n = 17: número de propriedades visitadas. 
utilizam utensílios de madeira. Em todas as propriedades, 100\% ( $\mathrm{n}=17)$, são utilizadas formas adaptadas para moldagem dos queijos, sendo essas em PVC ou aço inoxidável.

Ao verificar os utensílios utilizados na fabricação do queijo colonial nas propriedades pesquisadas, comparando-os com as exigências especificadas pela legislação (BRASIL, 2000), constatou-se que os locais de armazenamento desses utensílios, bem como a prática consolidada da utilização da madeira, apresentam-se insatisfatórias do ponto de vista higiênico-sanitário. Apesar de ser um produto artesanal, algumas adequações, como a do material utilizado, são importantes para atender as exigências da Resolução.

Foi verificado que 59\% $(n=10)$ das propriedades conservam os queijos até sua comercialização em geladeiras específicas, ou seja, geladeiras que eram utilizadas somente para o armazenamento do queijo. Em 41\% $(\mathrm{n}=7)$ das propriedades o armazenamento era feito em geladeiras da cozinha da propriedade, juntamente a outros tipos de alimentos e produtos refrigerados.

Considerando esses aspectos fundamentais associados às Boas Práticas de manipulação para fabricação de alimentos, constatou-se não existir nenhum programa de Boas Práticas implantado nas propriedades avaliadas. Apesar de, em algumas propriedades, alguns procedimentos serem adotados, tais como a "casa do queijo" separada da residência, geladeira exclusiva para os produtos (se comparado ao prejuízo de armazená-los na geladeira da residência), telas nas janelas, entre outros, as Boas Práticas ainda constituem um fator a ser melhorado para que a atividade de produção de queijos seja adequada aos parâmetros estabelecidos pela legislação.

No que tange ao controle de manipuladores, observou-se que nenhuma propriedade realizava esse controle. Segundo RIEDEL (2005), as contaminações ocorrem com maior frequência por meio de operadores que têm um contato próximo e constante com os alimentos. Foi notado nas visitas que os produtores entram e saem do ambiente e realizam atividades paralelas à fabricação do queijo, especialmente os que ainda o fazem dentro de sua própria casa.

No processo de fabricação também se observou o controle de pragas, que tem grande importância, pois através dele consegue-se controlar uma contaminação cruzada ou mesmo um foco de contaminação que pode ser gerado por pragas como, por exemplo, moscas, formigas, roedores, baratas, entre outros. Dentre as propriedades que possuem um local específico para produção dos queijos, $76 \%$ $(\mathrm{n}=12)$ realizam pelo menos uma medida para o controle de pragas, tais como janelas teladas, proteção nos ralos, ventilação e

Tabela 6 - Condições de produção dos queijos nas propriedades visitadas $\left(\mathrm{n}=17^{*}\right)$

\begin{tabular}{cccc}
\hline Exigências da IN30 & $\begin{array}{c}\text { Município 1 } \\
\mathrm{n}=12\end{array}$ & $\begin{array}{c}\text { Município 2 } \\
\mathrm{n}=03\end{array}$ & $\begin{array}{c}\text { Município 3 } \\
\mathrm{n}=02\end{array}$ \\
\hline Programa de Boas Práticas de Fabricação & 0 & 0 & 0 \\
Controle dos manipuladores & 0 & 0 & 0 \\
Controle de pragas & $11^{* *}$ & 0 & 0 \\
Processo de maturação adequado & 0 & 0 & 0 \\
\hline
\end{tabular}

$*_{\mathrm{n}}=17$ : número de propriedades visitadas.

**Realiza algum tipo de medida para controle de praga. 
iluminação adequadas. No entanto, raticidas e formicidas não são empregados nos arredores das dependências de fabricação do queijo artesanal nas propriedades estudadas.

Em relação à realização do processo de maturação dos queijos, observou-se que essa prática não é realizada em nenhuma dela. Os queijos eram mantidos em geladeira entre $6{ }^{\circ} \mathrm{C}$ a $8{ }^{\circ} \mathrm{C}$ e comercializados por todos os produtores na forma refrigerada entre 3 e 15 dias a partir da fabricação.

Para que ocorra a maturação, os queijos devem ser mantidos em ambientes com temperatura controlada, acima daquela utilizada para conservação do produto, para que as alterações enzimáticas ocorram nos queijos. Pode-se comprovar que em nenhuma das propriedades foi observada a realização do processo de maturação adequado, uma vez que todos os queijos avaliados eram conservados sob refrigeração.

Em $18 \%(n=3)$ das propriedades, o queijo era comercializado com apenas cinco dias após a data de fabricação e conservação em geladeira; $70 \%(n=12)$ dos produtores, $o$ comercializavam entre sete e quinze dias após a produção. Por fim, somente $12 \%(n=2)$ dos produtores comercializava o queijo após quinze dias de fabricação e conservação em geladeira.

De acordo com a IN30 (BRASIL, 2013) a produção de queijos elaborados a partir de leite cru, com período de maturação inferior a 60 (sessenta) dias, fica restrita a queijaria situada em região de indicação geográfica registrada ou tradicionalmente reconhecida, ou que seja propriedade certificada como livre de tuberculose e brucelose, de acordo com o disposto no Programa Nacional de Controle e Erradicação da Brucelose e Tuberculose Animal (PNCEBT), ou controlado para brucelose e tuberculose pelo Órgão Estadual de Defesa Sanitária Animal, o que não é o caso das propriedades avaliadas.

Ainda, segundo a legislação IN30 (BRASIL, 2013), permite-se que os queijos artesanais tradicionalmente elaborados a partir de leite cru sejam maturados por um período inferior a 60 (sessenta) dias, quando estudos técnico-científicos comprovarem que a redução do período de maturação não compromete a qualidade e a inocuidade do produto. Como não existem ainda estudos a respeito da inocuidade desses queijos avaliados, os mesmos não poderiam ser produzidos e nem comercializados com o tempo de fabricação que possuem. Estudos técnicocientíficos a respeito dessa condição inerentes a esses queijos devem ser realizados para subsidiar os produtores na melhoria do seu processo produtivo.

\section{Comercialização dos Queijos}

Os resultados da avaliação da comercialização dos queijos das propriedades visitadas são apresentados abaixo, na Tabela 7.

Visto que a IN30 não especifica forma adequada de embalagem e rotulagem para queijos artesanais, utilizamos como parâme-

Tabela 7 - Comercialização dos queijos nas propriedades visitadas $\left(\mathrm{n}=17^{*}\right)$

\begin{tabular}{cccc}
\hline Exigências da IN30 & $\begin{array}{c}\text { Município 1 } \\
\mathrm{n}=12\end{array}$ & $\begin{array}{c}\text { Município 2 } \\
\mathrm{n}=03\end{array}$ & $\begin{array}{c}\text { Município 3 } \\
\mathrm{n}=02\end{array}$ \\
\hline Embalagem adequada & 11 & 0 & $1^{* *}$ \\
Rotulagem adequada & 12 & 0 & 0 \\
\hline
\end{tabular}

*n $=17:$ número de propriedades visitadas. 
tro as normas da Agência Nacional de Vigilância Sanitária (ANVISA, 2002) aplicáveis aos demais tipos de queijo.

De uma forma geral, observou-se que $71 \%(\mathrm{n}=12)$ dos queijos avaliados possuem algum tipo de embalagem com rótulo, sendo que $65 \%(n=11)$ são embalados em filme de polietileno flexível e $6 \%(\mathrm{n}=1)$ são embalados em redes plásticas, sendo estas últimas consideradas inadequadas por não permitirem proteção externa do produto. Um total de 29\% $(\mathrm{n}=5)$ dos queijos avaliados não possuem nenhum tipo de embalagem ou rótulo.

Quando presente nos queijos, no entanto, os rótulos identificavam adequadamente os produtos e atendiam a todos os requisitos básicos que devem constar na rotulagem de alimentos, tais como a identificação do produtor e o selo do Serviço de Inspeção $\mathrm{Mu}$ nicipal (SIM). Os queijos devidamente rotulados e embalados foram encontrados apenas em propriedades do Município 1.

\section{CONCLUSÕES}

Nenhum dos produtores atende aos critérios estabelecidos pela legislação. Em alguns aspectos, as exigências da lei, como a comprovação técnico-científica necessária para permitir maturação inferior a 60 dias, são atualmente inacessíveis aos produtores visitados neste estudo. Nota-se, nesse e em outros casos, um abismo entre a legislação e a realidade do produtor.

Quanto aos produtores, nota-se que as medidas mais urgentes a serem tomadas em algumas propriedades seriam a separação do local de produção do queijo em relação à cozinha da residência, bem como melhorias nos locais de ordenha, além da adoção de melhores práticas de higiene pessoal. Alguns desses requisitos envolvem capacitação e conscientização e outros, ainda, um investimento financeiro, os quais muitos produtores não têm condições de realizar.
A análise das propriedades em diferentes municípios indica que muitas dessas adequações físicas e dos processos de produção e comercialização podem ser concretizadas, ao menos em partes, pela implementação de políticas públicas locais, aproveitando políticas estaduais e federais já existentes. Dentre os municípios estudados, certamente o Município 1 está mais próximo de atender a IN30.

\section{AGRADECIMENTOS}

Agradecemos aos produtores de queijos coloniais dos municípios visitados que se dispuseram a colaborar nesta pesquisa e o apoio das Secretarias de Agricultura e EMATER dos municípios do oeste da Cantuquiriguaçu por nos ajudar no levantamento de informações sobre as propriedades produtoras de queijo colonial.

\section{REFERÊNCIAS}

AGÊNCIA NACIONAL DE VIGILÂNCIA SANITÁRIA (ANVISA). Portaria no 326, de 30 de julho de 1997. Aprova o regulamento técnico sobre as condições higiênico-sanitárias e de boas práticas de fabricação para estabelecimentos produtores/ industrializadores de alimentos. Diário Oficial da República Federativa do Brasil, jul. 1997. Disponível em: <http://portal. anvisa.gov.br/documents/33916/388704/ Portaria\%2BSVS-MS \%2BN.\%2B326\% 2 Bde $\% 2$ B $30 \% 2$ Bde $\% 2$ BJulho\%2Bde $\%$ 2B 1997.pdf/87a 1 ab03-0650-4e67-9f3159d8be3de167>. Acesso em: 12 jun. 2017.

AGÊNCIA NACIONAL DE VIGILÂNCIA SANITÁRIA (ANVISA). Resolução de Diretoria Colegiada, RDC n ${ }^{\circ} 259$, de 20 de setembro de 2002. Aprova o regulamento técnico sobre rotulagem de alimentos embalados. Diário Oficial da República Federativa do Brasil, 23 nov. 2002. 
BEZERRA, J. R. M. V. Tecnologia da fabricação de derivados do leite. Departamento de Engenharia de Alimentos. Guarapuava: Unicentro, 2008.

BRASIL. Ministério da Agricultura Pecuária e Abastecimento. Secretaria Nacional de Inspeção de Produtos de Origem Animal. Resolução n ${ }^{\circ} 7$, de 28 de novembro de 2000. Aprova critérios de funcionamento e de controle da produção de queijarias, para seu relacionamento junto ao serviço de Inspeção Federal. Diário Oficial da República Federativa do Brasil, 02 jan. 2001.

BRASIL. Ministério da Agricultura Pecuária e Abastecimento. Circular n ${ }^{\circ} 175$ CGPE/ DIPOA, de 16 de maio de 2005. Procedimentos de Verificação dos Programas de Autocontrole. Diário Oficial da República Federativa do Brasil, 2005.

BRASIL. Ministério da Agricultura, Pecuária e Abastecimento. Programa Nacional de Controle e Erradicação da Brucelose e da Tuberculose Animal (PNCEBT). Organizadores, Vera Cecilia Ferreira de Figueiredo, José Ricardo Lôbo, Vitor Salvador Picão Gonçalves. Brasília: MAPA/SDA/DSA, 2006, $188 \mathrm{p}$.

BRASIL. Ministério da Agricultura, Pecuária e Abastecimento. Instrução Normativa $\mathrm{n}^{\mathrm{o}}$ 62, de 29 de dezembro de 2011. Aprova o Regulamento Técnico de Produção, Identidade e Qualidade do Leite tipo A, o Regulamento Técnico de Identidade e Qualidade de Leite Cru Refrigerado, o Regulamento Técnico de Identidade e Qualidade de Leite Pasteurizado e o Regulamento Técnico da Coleta de Leite Cru Refrigerado e seu Transporte a Granel, em conformidade com os Anexos desta Instrução Normativa. Diário Oficial da República Federativa do Brasil, 30 dez. 2011. Seção 1, p. 6.
BRASIL. Ministério da Agricultura Pecuária e Abastecimento. Instrução Normativa $n^{\circ}$ 30, de 07 de agosto de 2013. Trata dos novos procedimentos para registro de queijos artesanais tradicionalmente produzidos a partir de leite cru. Diário Oficial da República Federativa do Brasil, 08 ago. 2013, nº 152, Seção 1, pág. 19.

COSTA, E. O. Importância da mastite na produção leiteira do país. Revista da Educação Continuada do CRMV-SP, São Paulo, v. 1, p. 3-7, 1998.

ELMOSLEMANY, A. M. et al. The association between bulk tank milk analysis for raw milk quality and on-farm management practices. Preventive Veterinary Medicine, v. 95, p. 32-40, 2010.

FEITOSA, T. et al. Pesquisa de Salmonella sp., Listeria sp. e microrganismos indicadores higiênicos sanitários em queijos produzidos no estado do Rio Grande do Norte. Ciência e Tecnologia de Alimentos, v. 23, p. 162$165,2003$.

GUERREIRO, P. K. et al. Qualidade microbiológica de leite em função de técnicas profiláticas no manejo de produção. Ciências Agrotécnicas, v. 29, n. 1, p. 216-222, 2005.

HARTMANN, W. Características físico-químicas, microbiológicas, de manejo e higiene na produção de leite bovino na região oeste do Paraná: ocorrência de Listeria monocytogenes. 2009. 88p. Tese (doutorado em Tecnologia de Alimentos) - Universidade Federal do Paraná, Curitiba, 2009.

LISITA, M. O. Evolução da População Bacteriana na Linha de Produção do Queijo Minas Frescal em uma Indústria de Laticínios. 2005. 61p. Dissertação (Mestrado) - Escola Superior de Agricultura 
“Luiz Queiroz", Universidade de São Paulo, Piracicaba, 2005.

MOUSQUER, E. C. Aspectos de composição e avaliação das condições gerais de produção do queijo colonial por agricultores familiares na região oeste do Paraná. 2007. Monografia (especialização). Universidade Estadual do Oeste do Paraná, 2007.

OLIVEIRA, D. F. et al. Análise da composição físico-química, conteúdo lipídico e qualidade higiênico-sanitária de queijos coloniais. In: CONGRESSO NACIONAL DE TICÍNIOS, 27, 2010, Juiz de Fora. Anais... Juiz de Fora: EPAMIG/ILCT, 2010. 1 CDROM.

PIETROWSKI, G. de A. M. et al. Avaliação da qualidade microbiológica de queijo tipo mussarela comercializado na cidade de Ponta Grossa, Paraná. Revista Brasileira de Tecnologia Agroindustrial, v. 2, n. 2, p. 25-31, 2008.

RIEDEL, G. Controle sanitário de alimentos, Ed. Atheneu, $3^{\mathrm{a}}$ edição, São Paulo, p. 455, 2005.

SOUZA, C. F. V. et al. Changes in the microbiological and physicochemical characteristics of Serrano cheese during manufacture and ripening. Brazilian Journal of Microbiology, v. 34, n. 3, p. 260-266, 2003.

TESSER, I. C. Fabricação Artesanal e Avaliação Química e Microbiológica do Queijo Colonial produzido em Municípios do Oeste do território da Cantuquiriguaçu - Paraná/Brasil. 2014. 58p. Dissertação (mestrado em Desenvolvimento Rural Sustentável) - Universidade Estadual do Oeste do Paraná, Marechal Cândido Rondon, 2014.

TOMICH, R. G. P. et al. Metodologia para avaliação das boas práticas de fabricação em industrias de pão de queijo. Ciência Tecnologia de Alimentos, v. 25, n. 1, p. 115120, 2005.

TRONCO, V. M. Manual para a Inspeção da Qualidade do Leite. $5^{\text {a }}$ ed. Santa Maria: Ed. UFSM, 2013.

VIANA, C, E. Avaliação química e microbiológica do queijo colonial produzido no município de Realeza Paraná. Monografia (especialização). Universidade Estadual do Oeste do Paraná, 2013.

ZAFFARI, C. B et al. Qualidade bacteriológica de queijos artesanais comercializados em estradas do litoral norte do Rio Grande do Sul, Brasil. Revista Ciência Rural. Santa Maria, v. 37, n. 3, p. 862-867, 2007. 